OPEN ACCESS

Edited by:

Aiqin Wang,

Lanzhou Institute of Chemical Physics

(CAS), China

Reviewed by:

Peng Lu,

Ningbo University, China

Xiu Wen Cheng,

Lanzhou University, China

*Correspondence: Hongjun Lin hjlin@zjnu.cn

†These authors have contributed equally to this work

Specialty section: This article was submitted to Green and Sustainable Chemistry, a section of the journal

Frontiers in Chemistry

Received: 11 February 2020 Accepted: 09 March 2020

Published: 08 April 2020

Citation:

Shen L, Huang Z, Liu Y, Li R, Xu Y, Jakaj $G$ and $L$ in $H$ (2020) Polymeric Membranes Incorporated With ZnO Nanoparticles for Membrane Fouling Mitigation: A Brief Review. Front. Chem. 8:224

doi: $10.3389 /$ fchem.2020.00224

\section{Polymeric Membranes Incorporated With ZnO Nanoparticles for Membrane Fouling Mitigation: A Brief Review}

\author{
Liguo Shen ${ }^{\dagger}$, Zhengyi Huang ${ }^{\dagger}$, Ying Liu, Renjie Li, Yanchao Xu, Gjon Jakaj and \\ Hongjun Lin*
}

College of Geography and Environmental Sciences, Zhejiang Normal University, Jinhua, China

Due to the flexibility of operation, high removal ability, and economic cost, separation membranes have proved to be one of the most significant technologies in various aspects including water treatment. However, membrane fouling is a predominant barrier which is severely limiting the whole membrane industry. To mitigate membrane fouling, researchers have carried out several modification strategies including the incorporation of hydrophilic inorganic components. Zinc oxide $(\mathrm{ZnO})$ nanoparticles, known as a low-cost, environment-friendly, and hydrophilic inorganic material, have been used by worldwide researchers. As claimed by the scientific literatures, ZnO nanoparticles can not only endow the polymeric membranes with antifouling performance but also supply a photocatalytic self-cleaning ability. Therefore, polymer-ZnO composite membranes were considered to be an attractive hot topic in membrane technology. In the last decades, it has been significantly matured by a large mass of literature reports. The current review highlights the latest findings in polymeric membranes incorporated with $\mathrm{ZnO}$ nanoparticles for membrane fouling mitigation. The membrane fouling, $\mathrm{ZnO}$ nanoparticles, and modification technology were introduced in the first three sections. Particularly, the review makes a summary of the reports of polyvinylidene fluoride (PVDF)-ZnO composite membranes, polyethersulfone (PES)-ZnO composite membranes, and other composite membranes incorporated with $\mathrm{ZnO}$ nanoparticles. This review further points out several crucial topics for the future development of polymer-ZnO composite membranes.

Keywords: polymeric membrane, modification, $\mathrm{ZnO}$ nanoparticles, composite membrane, antifouling

\section{INTRODUCTION}

Water resource is currently facing an extreme scarcity crisis due to poor management, overuse, environmental degradation, contamination, and booming of the population (Eliasson, 2015; Vörösmarty et al., 2015). In anticipation of the rising negative consequences, various water treatment technologies are being conducted in response to the urgent growing stresses (Chong et al., 2010; Pendergast and Hoek, 2011). Comparing to the traditional water treatment technologies, pressure-driven membrane technology is attracting worldwide attention due to its obvious superiorities (Strathmann, 1981; Baker, 2002; Padaki et al., 2015). 


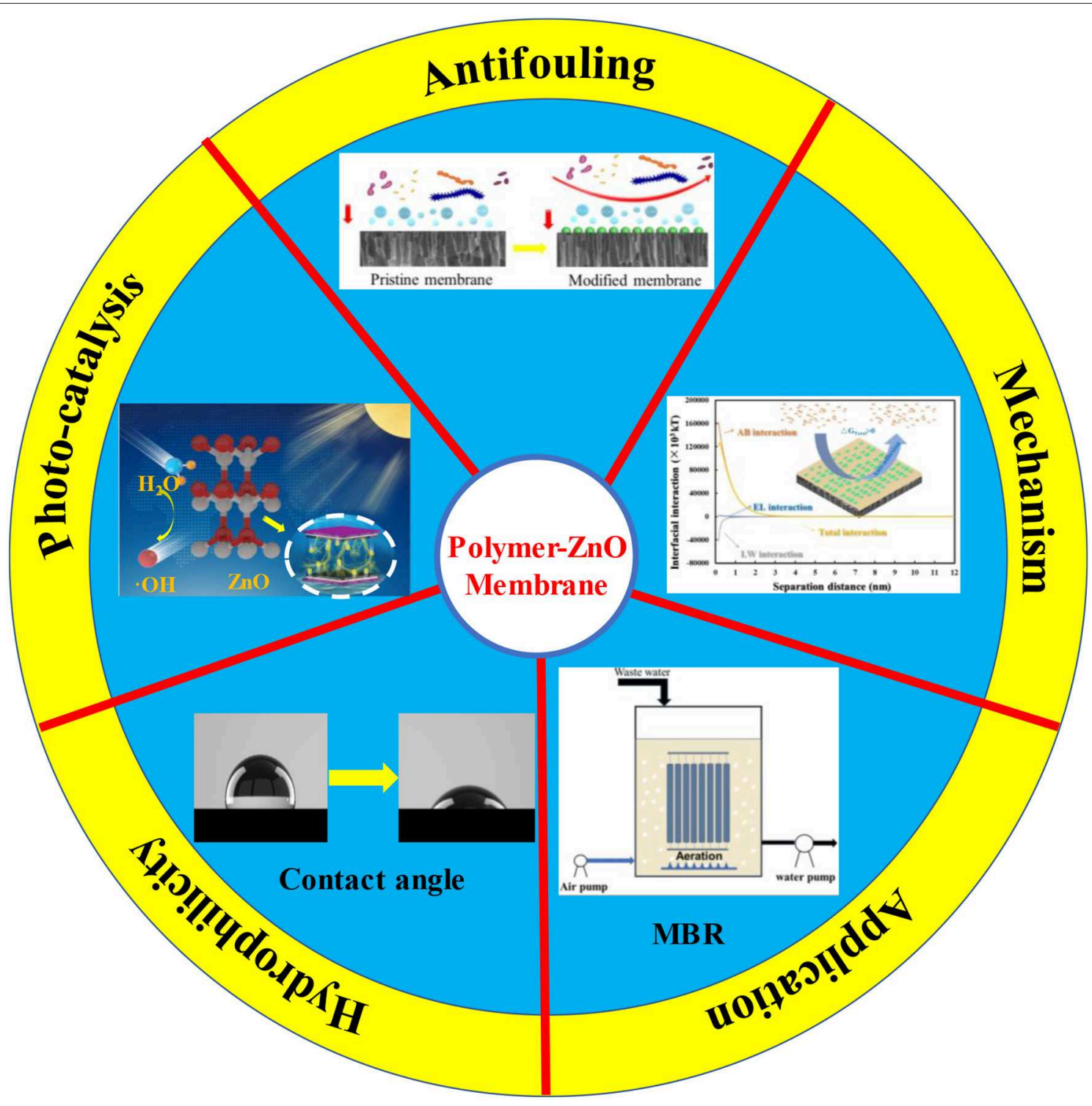

GRAPHICAL ABSTRACT | The study and applications of polymer-ZnO membranes.

Therefore, membrane separation technology has found extensive applications in the water treatment field (Ang et al., 2015; Subramani and Jacangelo, 2015; Tran et al., 2015).

Membrane can be defined as a physical interphase and acts as a selective barrier for different chemical species in a separation procedure. With a long period of development, membranes now appear in abundant categories, such as

Abbreviations: PVDF, polyvinylidene fluoride; PES, polyethersulfone; PVC, polyvinyl chloride; PS, polysulfone; PE, polyethylene; MF, microfiltration; UF, ultrafiltration; NF, nanofiltration; RO, reverse osmosis; DFT, density functional theory; CFD, computational fluid dynamics; ANN, artificial neural network; ALD, atomic layer deposition; BSA, bovine serum albumin; SA, sodium alginate; HA, humic acid; PU, polyurethane; CS, chitosan; GO, graphene oxide; NOM, natural organic matter; XDLVO, Derjaguin-Landau-Verwey-Overbeek. homogeneous or heterogeneous membranes; symmetric or asymmetric membranes (Lin et al., 2006); positively charged, negatively charged, or neutral membranes (Schaep and Vandecasteele, 2001). According to the membrane pore sizes, the pressure-driving membranes can beusually categorized into microfiltration membrane (MF), ultrafiltration membrane (UF), nanofiltration membrane $(\mathrm{NF})$, and reverse osmosis membrane (RO) (Van Der Bruggen et al., 2003). Generally, MF, UF, NF, and $\mathrm{RO}$ are applied to effectively reject suspended particles, macromolecules, multivalent ions, and monovalent ions from the water system, respectively.

Particularly, membranes are significantly differentiated through the membrane materials, such as inorganic ceramic membranes and organic polymeric membranes (Anderson et al., 
1988; Meng et al., 2009; Kim and Van der Bruggen, 2010; Lee et al., 2011; Kang and Cao, 2014). The organic polymers possess outstanding mechanical, physical, and chemical properties, therefore, become the widely used commercial materials. Recently, researchers have developed various polymeric membranes (Shao and Huang, 2007; Wang et al., 2013). Among the polymeric membranes, it is believed that polyethersulfone (PES) and polyvinylidene fluoride (PVDF) mainly occupy the membrane market. The inorganic membranes are usually made from ceramic materials such as $\mathrm{Al}_{2} \mathrm{O}_{3}, \mathrm{SiO}_{2}$, or $\mathrm{TiO}_{2}$ nanoparticles and so on (Mallada and Menéndez, 2008). Comparing to polymeric membranes, they cannot find extensive applications due to their exorbitant price and fragility which threatens the integrity of membranes. Therefore, polymeric membranes are attracting more and more worldwide attention.

However, the membrane fouling is seriously limiting the development of polymeric membranes due to their intrinsic hydrophobicity which favors to adhere the hydrophobic natural organic matters (NOMs) (Lin et al., 2013; She et al., 2016). In view of this, researchers make their efforts to hydrophilization modification via various methods (Zhao et al., 2013; Kang and Cao, 2014). Especially, the combination of polymer and nanoparticles was verified to be a successful strategy to enhance membrane hydrophilicity (Cuiming et al., 2003; Wu et al., 2003). Recently, this strategy is becoming more and more popular in antifouling research (Kango et al., 2013; $\mathrm{Ng}$ et al., 2013; Duan et al., 2015). Based on the abundant literatures, $\mathrm{TiO}_{2}$ nanocomposite-based polymeric membranes have already been well-studied and reviewed by previous reports (Kwak et al., 2001; Leong et al., 2014; Bet-Moushoul et al., 2016). Meanwhile, plenty of research articles have proved that zinc oxide $(\mathrm{ZnO})$ nanoparticles, with one-fourth the cost of $\mathrm{TiO}_{2}$, presented comparable physical and chemical properties with $\mathrm{TiO}_{2}$ (Hong and $\mathrm{He}, 2014$ ). Therefore, $\mathrm{ZnO}$ nanoparticles are believed to be a competitive alternative to $\mathrm{TiO}_{2}$ nanoparticles in the formation of antifouling organic-inorganic composite membranes (Balta et al., 2012). Although extensive articles have developed polymer- $\mathrm{ZnO}$ composite membranes for antifouling applications (Leo et al., 2012; Zhao S. et al., 2015), a comprehensive review of literature of polymer- $\mathrm{ZnO}$ composite membranes is still limited and highly desired in the membrane field.

This review will highlight the latest findings in polymeric membranes incorporated with $\mathrm{ZnO}$ nanoparticles for membrane fouling mitigation. The membrane fouling, $\mathrm{ZnO}$ nanoparticles, and modification technology were introduced in the first three sections. Particularly, the review introduced the reports of PVDF-ZnO composite membranes, PES-ZnO composite membranes, and other composite membranes incorporated with $\mathrm{ZnO}$ nanoparticles. The current study further points out several crucial topics for the future development of polymer- $\mathrm{ZnO}$ composite membranes.

\section{MEMBRANE FOULING}

Membrane fouling, the most troublesome problem for the whole membrane technology industry (Gao et al., 2011; Tijing et al., 2015), extremely cripples the membrane performance and drastically increases the operation costs. The membrane fouling resulted from a complicated interaction process between the membrane and the foulant during the filtration operation (Lin H. et al., 2014). The complicated interaction process is commonly involved with many characteristics, such as membrane pore/surface structure, pollutant conditions, charge property, and particularly the hydrophobicity (Chen et al., 2016; Teng et al., 2020; You et al., 2020). To simplify an extremely complicated process, researchers studied the membrane fouling from external fouling and internal fouling ( $\mathrm{Ma}$ et al., 2001).

Membrane fouling usually occurs through the deposition of foulant sediments from wastewater onto the membrane surface, which results in a "cake layer," known as external fouling. However, some small foulant particles go into the sublayer of the membrane and eventually adhere onto the pore walls during the filtration process. Moreover, the foulant materials at the porous support layer can further combine with the previously adsorbed particles. In this way, it will lead to "pore-clogging," which is known as internal fouling. Comparing with the external fouling, the internal fouling is less reversible (Kimura et al., 2004; Shirasaki et al., 2008). The backwash method has been developed for the removal of the foulant within the support layer (Crozes et al., 1997; Smith et al., 2006; Hwang et al., 2009). It displays an efficient removal for the external fouling on the membrane surface but cannot efficiently remove the internal fouling. Recently, it is found that the surface modification can promote the hydrophilic ability of membrane and has displayed successfully applications in reducing the external fouling (Ma et al., 2001; Shen et al., 2017a). However, internal fouling control remains in a complicated situation and is still an attractive research topic for future studies.

To obtain a hydrodynamic understanding of the membrane fouling, an interpretation of the membrane fouling mechanism can be now developed from the extended Derjaguin-LandauVerwey-Overbeek (XDLVO) theory (Lee et al., 2007; Hong et al., 2013; Lin T. et al., 2014). Based on the XDLVO theory, the fouling process can be quantitatively evaluated via the interface thermodynamic reactions (Shen et al., 2015, 2017b; Yu et al., 2019). Theoretically, a membrane that presents lower roughness, an enhanced negative charge, and a hydrophilic surface will show less adhesion force toward NOM present in wastewater (Zhang et al., 2015). Recently, researchers employed more methods to explain the membrane fouling mechanism such as density functional theory (DFT), computational fluid dynamics (CFD), artificial neural network (ANN), and combined methods (Ghidossi et al., 2006; Teng et al., 2018; Zhang et al., 2018; Chen et al., 2019; Li et al., 2019). These theoretical results not only give out a quantitative interpretation to membrane fouling process but also can direct the modification of membranes.

\section{ZINC OXIDE NANOPARTICLES}

$\mathrm{ZnO}$, as an outstanding material (Look, 2001), has been widely used in photocatalysis and antifouling purposes ( $\mathrm{Wu}$ and Xue, 2011). Moreover, the high surface-to-volume ratio of $\mathrm{ZnO}$ nanoparticles makes it a significant candidate in various fields 
(Ko et al., 2011). With one-fourth the cost of $\mathrm{TiO}_{2}, \mathrm{ZnO}$ nanoparticles have been even considered to be an important alternative to $\mathrm{TiO}_{2}$ (Hong and $\mathrm{He}, 2014$ ). $\mathrm{ZnO}$ nanoparticles possess a strong hydrophilicity by adhering the hydrophilic functional groups such as $-\mathrm{OH},-\mathrm{SO}_{3} \mathrm{H}$, and $-\mathrm{COOH}$ (Shen et al., 2012). Thanks to the outstanding properties of $\mathrm{ZnO}$ nanoparticles, an increasing number of researchers are able to promote the membrane's antifouling ability by combining $\mathrm{ZnO}$ nanoparticles with the polymeric membrane (Liang et al., 2012).

\section{MODIFICATION TECHNOLOGY}

Since fouling happens at the surface and inside of the membranes, the modification strategies are generally classified into two types: external/surface modification and internal/bulk modification technologies.

For internal modification, the casting membrane solution is firstly mixed with a certain amount of $\mathrm{ZnO}$ nanoparticles, then transferred to a glass plate for the membrane preparation via the phase inversion method. By this method, the $\mathrm{ZnO}$ nanoparticles were embedded into the whole polymeric networks. Very small amounts of $\mathrm{ZnO}$ nanoparticles were observed at the membrane, which could be attributed to the solvent/non-solvent exchange process. This exchange process is an easy-going method without additional chemicals which are environmentally unfriendly and increasing cost. Therefore, this method has been employed by many researchers and reveals a great potential for further applications. For example, Ahmad et al. (2015) dispersed hydrophilic $\mathrm{ZnO}$ nanoparticles (0-3.75 wt.\%) into PES casting solution to prepare a hydrophilic and antifouling composite membrane. Moreover, Hong and He (2012) modified PVDF membranes by the addition of $0-1$ wt.\% $\mathrm{ZnO}$ nanoparticles via the phase inversion method. Researchers have also tried to introduce $\mathrm{ZnO}$ nanoparticles into various types of polymeric materials, such as polyvinyl chloride (PVC) (Rabiee et al., 2015), polystyrene (PS) (Leo et al., 2012), polyethylene (PE) (Jafarzadeh et al., 2015), and so on. The internal modification reveals many advantages and delivers a reliable candidate method for preparing the $\mathrm{ZnO}$ incorporated polymeric membranes. However, some critical and intractable problems still need to be dealt with. One of the key problems is the aggregation of nanoparticles, which is the nature of all nanoparticles and greatly limits the filtration capacity of $\mathrm{ZnO}$ in the polymeric membranes (Liang et al., 2012). In addition, the leaking of $\mathrm{ZnO}$ nanoparticles is an additional problem that appears during the application of composite membranes. The $\mathrm{ZnO}$ nanoparticles are usually embedded into the polymeric network through a physical interaction that is not strong enough to fasten all the $\mathrm{ZnO}$ nanoparticles. As a result, nanoparticles are always discharged during the filtration process. Therefore, overcoming aggregation and leaking of $\mathrm{ZnO}$ nanoparticles in the polymeric membrane is a key research topic in the future of $\mathrm{ZnO}$ nanoparticle-modified polymeric membranes.

The external modification refers to physically or chemically coating hydrophilic components onto the membrane surface (Yu et al., 2019; Zhao et al., 2019). During the membrane fouling process, pollutants firstly get closer to the membrane surface, then interact with the membrane surface, and eventually adhere to the membrane surface. In view of this, it is claimed that the membrane surface is the critical functional layer which mainly determines the membrane fouling ability (Elimelech et al., 1997). Accordingly, modification of the membrane surface plays a more directive and more efficient role for membrane antifouling. Based on this concept, the surfacemodified polymeric membranes by $\mathrm{ZnO}$ nanoparticles have been developed and show great promotion in antifouling ability. Since the $\mathrm{ZnO}$ nanoparticles are located on the membrane surface, their efficiency is largely enhanced during the antifouling process. Another prominent advantage is the possibility to chemically bond the $\mathrm{ZnO}$ nanoparticles on the membrane surface via bridging the chemical reaction between $\mathrm{ZnO}$ nanoparticles and the polymeric membrane. For example, Li et al. (2016) employed the atomic layer deposition (ALD) technique to modify the PVDF membrane surface. By this technique, an ultrathin $\mathrm{ZnO}$ layer can be efficiently formed on the membrane surface after 10 ALD cycles. Therefore, the membrane's hydrophilicity and separation performance were significantly enhanced. Unlike the internal modification, the surface modification method requires complicated experimental operations and additional chemicals that are not good to a competitive membrane cost. From the experimental results, it can be concluded that internal modification is an easier method to obtain enhanced antifouling membrane; however, the higher efficiency and the larger selectivity of grafting agents ensure the surface modification method to be the preferred adopted method. To obtain the synergetic advantages of external and internal modification, a novel strategy has been developed by using the external magnetic field which can fix the magnetic nanoparticles onto the membrane surface. Recently, this novel concept has been used to polymer-carbon nanotube membranes (Yu et al., 2020) and polymer-graphene oxide membranes (Xu et al., 2016). It is believed that it will have a potential application in polymer$\mathrm{ZnO}$ membranes.

\section{ZINC OXIDE-INCORPORATED POLYMERIC MEMBRANES}

\section{Polyvinylidene Fluoride Membrane Incorporated With Zinc Oxide Nanoparticles}

PVDF has been extensively applied in separation technology for various purposes (Liu et al., 2011; Kang and Cao, 2014). However, the membrane fouling is shortening PVDF membranes' lifetime and increasing operation cost, which is widely considered to be the bottleneck problem obstacle for PVDF membranes in water treatment. The critical surface tension $(\gamma c)$ of PVDF is $31 \mathrm{mN} \cdot \mathrm{m}^{-2}$ which represents the strong hydrophobic nature of the PVDF membrane (Liu et al., 2011). Obviously, the hydrophobic property of PVDF membranes is one significant cause of membrane fouling and limited applications (Chang et al., 2008; Du et al., 2009; Yuliwati and Ismail, 2011). Therefore, 
many efforts have been committed to combining $\mathrm{ZnO}$ with PVDF membranes for antifouling enhancement.

Hong and $\mathrm{He}$ (2014) prepared PVDF-ZnO composite membranes by a blending process. All membranes exhibited typical asymmetric cross-section structures. It was found that addition of $\mathrm{ZnO}$ nanoparticles caused smaller water contact angles (enhanced hydrophilicity) and, therefore, can result in promoted antifouling ability. Moreover, the PVDF-ZnO composite membranes possessed looser sublayer structures, which is helpful to promote the filtration performance. It is well-known that membrane porosity is a positive correlation with exchange velocity of solvent/non-solvent. The hydrophilic $\mathrm{ZnO}$ nanoparticles can accelerate the importation of water to casting membrane because they have a higher affinity with water. Meanwhile, the solvents flow out of the casting membrane in a higher speed. In this way, the hydrophilic $\mathrm{ZnO}$ nanoparticles promoted the exchange velocity, therefore causing larger cavities, which promise the looser sublayer and higher membrane flux. Additionally, $\mathrm{ZnO}$ nanoparticles are good photochemical catalysts which can be used as a photocatalytic self-cleaning of the PVDF membranes. Hong and $\mathrm{He}$ (2014) studied the photocatalytic self-cleaning performance of PVDF- $\mathrm{ZnO}$ membranes. They found that the photocatalytic self-cleaning can supply a $93 \%$ washing efficiency to the PVDF membrane. The reason is that the ultraviolet can display an effective degradation to the adsorbed pollutants on the membrane due to the excellent photocatalytic property of $\mathrm{ZnO}$ nanoparticles.

Liang et al. (2012) mixed $\mathrm{ZnO}$ nanoparticles with PVDF to prepare PVDF-ZnO composite membranes to tackle irreversible membrane fouling. The experimental results indicated that water permeability of all four modified membranes was greatly improved because $\mathrm{ZnO}$ nanoparticles promoted the hydrophilicity of PVDF materials. But excess addition of $\mathrm{ZnO}$ nanoparticles can result in a slight permeability loss due to aggregations. After a simple physical cleaning, the permeation recovery rate of the modified membranes can reach to $100 \%$, while that of the control PVDF membrane was only about $78 \%$. This indicates that the PVDF- $\mathrm{ZnO}$ composite membranes have an obvious advantage in anti-irreversible fouling which is the intractable problem in membrane applications.

Zhang et al. (2014) prepared PVDF-ZnO composite membranes by internal and external modification methods. The static protein adsorption experiments revealed that control PVDF membrane had a bovine serum albumin (BSA) adsorption capacity of $0.128 \mathrm{mg} \cdot \mathrm{cm}^{-2}$, whereas the PVDF-ZnO composite membrane showed the minimum adsorption capacity of 0.035 $\mathrm{mg} \cdot \mathrm{cm}^{-2}$. In addition, it was found that PVDF-ZnO composite membranes demonstrated higher adsorption property to heavy metal ions.

\section{Polyethersulfone Membrane Incorporated With Zinc Oxide}

The presence of aromatic groups in PES determines the outstanding chemical and mechanical stability. Moreover, the PES possesses advantage in oxidative, thermal, and hydrolytic stability. For example, the high glass transition temperature of
PES reaches to $230^{\circ} \mathrm{C}$. Nevertheless, membrane fouling is the major problem for PES membranes as well as for other polymeric membranes. Therefore, many studies have been published to explore PES membrane modified with $\mathrm{ZnO}$ nanoparticles for antifouling purposes.

Zhao S. et al. (2015) fabricated PES-ZnO composite membranes and found that PES-ZnO composite membranes displayed a more porous membrane structure. The dynamic water contact angle showed that the PES-ZnO composite membranes presented better hydrophilicity than pristine PES membrane. The strengthened surface hydrophilicity was attributed to the addition of $\mathrm{ZnO}$ nanoparticles. Moreover, compared with pristine PES membranes, PES-ZnO membranes' thermal stability was improved.

Li et al. (2015) firstly synthesized 10-nm $\mathrm{ZnO}$ nanoparticles by a sol-gel method. After that, they introduced the $\mathrm{ZnO}$ nanoparticles into polymer membranes. The permeability was promoted from 46.4 to $365.8 \mathrm{~L} \cdot \mathrm{m}^{-2} \mathrm{~h}^{-1}$. To investigate the fouling behavior of the fabricated membranes, three model solutions were used as organic foulant mediums (Zhao L. H. et al., 2015). The flux loss rate and flux loss degree of PES$\mathrm{ZnO}$ composite membranes were significantly reduced after the filtration of all the pollutant solutions. It is known that removal of BSA fouling from the membrane is more difficult. However, flux recovery rate of the optimal composite membrane reached to $80 \%$ by a simple physical wash, while the flux recovery rate for pristine membrane was only around $25 \%$. Moreover, the PES-ZnO composite membranes possessed $83 \%$ flux recovery rate to the mixture solution of sodium alginate (SA), humic acid (HA), and $\mathrm{BSA}$, which indicates that the PES-ZnO composite membranes can be a potential application in the real water treatments.

In our previous work (Shen et al., 2012), the experiments verified that the hydrophilicity of PES-ZnO membrane was considerably enhanced by the water contact angle reduction from $79.92^{\circ}$ to $54.86^{\circ}$. The composite membrane exhibited high water flux $\left(125.40 \mathrm{~kg} \cdot \mathrm{m}^{-2}\right)$ which represented a promotion of $254 \%$ without sacrificing the membrane rejection. The control membrane suffered $27.7 \%$ flux decrease, however, the optimal PES-ZnO membrane with $0.3 \mathrm{~g} \mathrm{ZnO}$ displayed only $7.8 \%$ flux decrease, which means that the antifouling ability was improved by the addition of $\mathrm{ZnO}$ nanoparticles.

In order to fix the $\mathrm{ZnO}$ nanoparticles on the membrane surface, Jo et al. (2016) firstly introduced $\mathrm{NH}_{2}$ into PES and then chemically assembled $\mathrm{ZnO}$ nanoparticles onto the membrane surface. The pristine PES membrane did not show obvious antibacterial ability, which was evidenced by the antibacterial activity rates against Escherichia coli and Staphylococcus aureus that were 0.21 and 0.20 , respectively. When the $\mathrm{ZnO}$ was added, the antibacterial activity of composite membrane rapidly increased to 6.1 for both E. coli and S. aureus.

Balta et al. (2012) found that $\mathrm{ZnO}$-modified membranes showed an overall improvement by ultralow concentration addition. In addition, they found that the $\mathrm{ZnO}$ nanoparticles caused a significant effect on the membrane substructure via affecting the phase inversion process. Ahmad et al. (2015) incorporated $\mathrm{ZnO}$ nanoparticles into PES to significantly improve the treatment performance for humic acid (HA) 
solution. They also found that all the composite membranes displayed a superiority to control membrane. For example, the composite membranes not only presented high water flux but also had higher rejection. Moreover, they exhibited promoted antifouling ability during the filtration process of HA solutions.

\section{Other Polymeric Membranes Incorporated With Zinc Oxide}

Kim et al. (2018) developed the polyurethane (PU)- $\mathrm{ZnO}$ composite material via combined surface modification technologies. The composite membrane revealed significant photocatalytic/antimicrobial activity which was favorable to a potential application in organic pollutant degradation and wastewater purification. Since the compatibility of the organic-inorganic material is a general concern, Li et al. (2010) studied the mechanical properties of a novel chitosan (CS)-ZnO nanoparticle composite membrane prepared by a sol-casting method. The dry and wet samples were tested by tensile strength and elongation, respectively. It was interestingly found that the composite membranes possessed an enhanced mechanical property, which was attributed to intramolecular and intermolecular hydrogen bonds. After the introduction of $\mathrm{ZnO}$, the intermolecular hydrogen bond between chitosan molecules was weakened; meanwhile, the hydrogen bond between CS and $\mathrm{ZnO}$ was enhanced. Nevertheless, excessive addition of $\mathrm{ZnO}$ can make the composite membranes brittle. Besides, the tests of Bacillus subtilis, E. coli, and S. aureus obviously presented that $\mathrm{ZnO}$ provided significant antibacterial ability.

Graphene oxide (GO), as one of the most popular materials (Dreyer et al., 2010; Chabot et al., 2014; Li et al., 2020), was combined with $\mathrm{ZnO}$ by Mahlangu et al. (2017). The GO-ZnO nanocomposites were impregnated in the membrane to increase the drug repellent properties by reducing the membrane-solute hydrophobic interaction. When the membrane and organic matters had the same type of charges, the repulsion at the interface played a role to promote the solute rejection. However, the organic matter with opposite zeta potential to the membrane was still adhered on the membrane surface, which could be caused by the concentration polarization. The composite membrane possessed enhanced hydrophilicity, permeability, and antifouling ability to the pristine membrane.

Pintilie et al. (2018) tried to compare the effects of $\mathrm{ZnO}$ and $\mathrm{TiO}_{2}$ on the polysulfone (PS) membranes. In the experiments, the composite membranes were prepared by blending PS with $\mathrm{ZnO}, \mathrm{TiO}_{2}$ nanoparticles, and $\mathrm{ZnO}-\mathrm{TiO}_{2}$ hybrid particles. They claimed that $\mathrm{ZnO}-\mathrm{TiO}_{2}$ had a more efficient effect on PS membrane than that of $\mathrm{ZnO}$ and $\mathrm{TiO}_{2}$ nanoparticles. This

\section{REFERENCES}

Ahmad, A. L., Abdulkarim, A. A., Ismail, S., and Ooi, B. S. (2015). Preparation and characterisation of PES-ZnO mixed matrix membranes for humic acid removal. Desalin Water Treat. 54, 3257-3268. doi: 10.1080/19443994.2014. 910137

Anderson, M. A., Gieselmann, M. J., and Xu, Q. (1988). Titania and alumina ceramic membranes. J. Membr. Sci. 39, 243-258. doi: 10.1016/S0376-7388(00)80932-1 was attributed to the synergetic effect of $\mathrm{ZnO}$ and $\mathrm{TiO}_{2}$ nanoparticles. By a detailed observing, it was found that $\mathrm{ZnO}$ nanoparticles played a comparable or better role in promotion of membrane performance than the widely used $\mathrm{TiO}_{2}$ nanoparticles. This study sufficiently verifies that the $\mathrm{ZnO}$ nanoparticle is a successful alternative to $\mathrm{TiO}_{2}$ nanoparticle in modifying polymeric membranes.

\section{CONCLUSION}

In the last decade, the polymer- $\mathrm{ZnO}$ composite membranes have been significantly adopted by a large mass of literature reports. Therefore, the current review makes a summary of the latest findings in polymeric membranes incorporated with $\mathrm{ZnO}$ nanoparticles for membrane fouling mitigation. Firstly, the membrane fouling, $\mathrm{ZnO}$ nanoparticles, and modification technologies were introduced. After that, the review made intensive discussions on PVDF- $\mathrm{ZnO}$ composite membranes, PES-ZnO composite membranes, and other composite membranes incorporated with $\mathrm{ZnO}$ nanoparticles. These reports revealed that $\mathrm{ZnO}$ nanoparticles can endow polymeric membranes with significant hydrophilic, photocatalytic, and antimicrobial activities which were favorable to a potential application in wastewater treatments. For future development, the current review gives out several crucial topics: (a) overcoming aggregation and leaking of $\mathrm{ZnO}$ nanoparticles in the polymeric membrane is a key research topic in the future of $\mathrm{ZnO}$ nanoparticle-modified polymeric membranes; (b) antifouling mechanism research is another key topic since it can not only supply a sufficient explanation to the antifouling results but also direct the modification of membranes; (c) the longterm application research should be strengthened in view of the antifouling performance in previous studies that was primarily evaluated in short-term laboratory tests through the model solutions.

\section{AUTHOR CONTRIBUTIONS}

All authors listed have made a substantial, direct and intellectual contribution to the work, and approved it for publication.

\section{FUNDING}

This work was supported by the National Natural Science Foundation of China (Nos. 51978628, 21506195, 51578509) and the Zhejiang Provincial Natural Science Foundation of China (Nos. LGG19E030008, LQ17E080004) are highly appreciated.

Ang, W. L., Mohammad, A. W., Hilal, N., and Leo, C. P. (2015). A review on the applicability of integrated/hybrid membrane processes in water treatment and desalination plants. Desalination 363, 2-18. doi: 10.1016/j.desal.2014.03.008

Baker, R. W. (2002). Future directions of membrane gas separation technology. Ind. Eng. Chem. Res. 41, 1393-1411. doi: 10.1021/ie010 8088

Balta, S., Sotto, A., Luis, P., Benea, L., Van der Bruggen, B., and Kim, J. (2012). A new outlook on membrane enhancement with nanoparticles: the alternative of ZnO. J. Membr. Sci. 389, 155-161. doi: 10.1016/j.memsci.2011.10.025 
Bet-Moushoul, E., Mansourpanah, Y., Farhadi, K., and Tabatabaei, M. (2016). $\mathrm{TiO}_{2}$ nanocomposite based polymeric membranes: a review on performance improvement for various applications in chemical engineering processes. Chem. Eng. J. 283, 29-46. doi: 10.1016/j.cej.2015.06.124

Chabot, V., Higgins, D., Yu, A., Xiao, X., Chen, Z., and Zhang, J. (2014). A review of graphene and graphene oxide sponge: material synthesis and applications to energy and the environment. Energy Environ. Sci. 7, 1564-1596. doi: $10.1039 / \mathrm{c} 3 e e 43385 \mathrm{~d}$

Chang, Y., Shih, Y.-J., Ruaan, R.-C., Higuchi, A., Chen, W.-Y., and Lai, J.Y. (2008). Preparation of poly(vinylidene fluoride) microfiltration membrane with uniform surface-copolymerized poly(ethylene glycol) methacrylate and improvement of blood compatibility. J. Membr. Sci. 309, 165-174. doi: 10.1016/j.memsci.2007.10.024

Chen, J., Zhang, M., Li, F., Qian, L., Lin, H., Yang, L., et al. (2016). Membrane fouling in a membrane bioreactor: high filtration resistance of gel layer and its underlying mechanism. Water Res. 102, 82-89. doi: 10.1016/j.watres.2016.06.028

Chen, Y., Teng, J., Shen, L., Yu, G., Li, R., Xu, Y., et al. (2019). Novel insights into membrane fouling caused by gel layer in a membrane bioreactor: Effects of hydrogen bonding. Bioresour. Technol. 276, 219-225. doi: 10.1016/j.biortech.2019.01.010

Chong, M. N., Jin, B., C., Chow, W. K., and Saint, C. (2010). Recent developments in photocatalytic water treatment technology: a review. Water Res. 44, 2997-3027. doi: 10.1016/j.watres.2010.02.039

Crozes, G. F., Jacangelo, J. G., Anselme, C., and Laîné, J. M. (1997). Impact of ultrafiltration operating conditions on membrane irreversible fouling. J. Membr. Sci. 124, 63-76. doi: 10.1016/S0376-7388(96)00244-X

Cuiming, W., Tongwen, X., and Weihua, Y. (2003). Fundamental studies of a new hybrid (inorganic-organic) positively charged membrane: membrane preparation and characterizations. J. Membr. Science. 216, 269-278. doi: 10.1016/S0376-7388(03)00082-6

Dreyer, D. R., Park, S., Bielawski, C. W., and Ruoff, R. S. (2010). The chemistry of graphene oxide. Chem. Soc. Rev. 39, 228-240. doi: 10.1039/B91 $7103 \mathrm{G}$

Du, J. R., Peldszus, S., Huck, P. M., and Feng, X. (2009). Modification of poly(vinylidene fluoride) ultrafiltration membranes with poly(vinyl alcohol) for fouling control in drinking water treatment. Water Res. 43, 4559-4568. doi: 10.1016/j.watres.2009.08.008

Duan, J., Pan, Y., Pacheco, F., Litwiller, E., Lai, Z., and Pinnau, I. (2015). Highperformance polyamide thin-film-nanocomposite reverse osmosis membranes containing hydrophobic zeolitic imidazolate framework-8. J. Membr. Sci. 476, 303-310. doi: 10.1016/j.memsci.2014.11.038

Eliasson, J. (2015). The rising pressure of global water shortages. Nature. 517, 6 . doi: $10.1038 / 517006 a$

Elimelech, M., Xiaohua, Z., Childress, A. E., and Seungkwan, H. (1997). Role of membrane surface morphology in colloidal fouling of cellulose acetate and composite aromatic polyamide reverse osmosis membranes. J. Membr. Sci. 127, 101-109. doi: 10.1016/S0376-7388(96)00351-1

Gao, W., Liang, H., Ma, J., Han, M., Chen, Z. L., Han, Z. S., et al. (2011). Membrane fouling control in ultrafiltration technology for drinking water production: a review. Desalination 272, 1-8. doi: 10.1016/j.desal.2011.01.051

Ghidossi, R., Veyret, D., P. J., and Moulin, C. E., Intensification, P. P. (2006). Computational fluid dynamics applied to membranes: state of the art and opportunities. Chem. Eng. Process. 45, 437-454. doi: 10.1016/j.cep.2005. 11.002

Hong, H., Peng, W., Zhang, M., Chen, J., He, Y., Wang, F., Weng, X., Yu, H., and Lin, H. (2013). Thermodynamic analysis of membrane fouling in a submerged membrane bioreactor and its implications. Biores. Technol. 146, 7-14. doi: 10.1016/j.biortech.2013.07.040

Hong, J., and He, Y. (2014). Polyvinylidene fluoride ultrafiltration membrane blended with nano- $\mathrm{ZnO}$ particle for photo-catalysis self-cleaning. Desalination 332, 67-75. doi: 10.1016/j.desal.2013.10.026

Hong, J. M., and He, Y. (2012). Effects of nano sized zinc oxide on the performance of PVDF microfiltration membranes. Desalination 302, 71-79. doi: 10.1016/j.desal.2012.07.001

Hwang, K.-J., Chan, C.-S., and Tung, K.-L. (2009). Effect of backwash on the performance of submerged membrane filtration. J. Membr. Sci. 330, 349-356. doi: 10.1016/j.memsci.2009.01.012
Jafarzadeh, Y., Yegani, R., and Sedaghat, M. (2015). Preparation, characterization and fouling analysis of $\mathrm{ZnO} /$ polyethylene hybrid membranes for collagen separation. Chem. Eng. Res. Des. 94, 417-427. doi: 10.1016/j.cherd.2014.08.017

Jo, Y. J., Choi, E. Y., Kim, S. W., and Kim, C. K. (2016). Fabrication and characterization of a novel polyethersulfone/aminated polyethersulfone ultrafiltration membrane assembled with zinc oxide nanoparticles. Polymer. 87, 290-299. doi: 10.1016/j.polymer.2016.02.017

Kang, G.-D., and Cao, Y.-M. (2014). Application and modification of poly(vinylidene fluoride) (PVDF) membranes - a review. J. Membr. Sci. 463, 145-165. doi: 10.1016/j.memsci.2014.03.055

Kango, S., Kalia, S., Celli, A., Njuguna, J., Habibi, Y., and Kumar, R. (2013). Surface modification of inorganic nanoparticles for development of organicinorganic nanocomposites-a review. Progr. Polymer Sci. 38, 1232-1261. doi: 10.1016/j.progpolymsci.2013.02.003

Kim, J., and Van der Bruggen, B. (2010). The use of nanoparticles in polymeric and ceramic membrane structures: Review of manufacturing procedures and performance improvement for water treatment. Environ. Pollut. 158, 2335-2349. doi: 10.1016/j.envpol.2010.03.024

Kim, J. H., Joshi, M. K., Lee, J., Park, C. H., and Kim, C. S. (2018). Polydopamineassisted immobilization of hierarchical zinc oxide nanostructures on electrospun nanofibrous membrane for photocatalysis and antimicrobial activity. J. Colloid Interface Sci. 513, 566-574. doi: 10.1016/j.jcis.2017.11.061

Kimura, K., Hane, Y., Watanabe, Y., Amy, G., and Ohkuma, N. (2004). Irreversible membrane fouling during ultrafiltration of surface water. Water Res. 38, 3431-3441. doi: 10.1016/j.watres.2004.05.007

Ko, S. H., Lee, D., Kang, H. W., Nam, K. H., Yeo, J. Y., Hong, S. J., et al. (2011). Nanoforest of hydrothermally grown hierarchical $\mathrm{ZnO}$ nanowires for a high efficiency dye-sensitized solar cell. Nano Lett. 11, 666-671. doi: $10.1021 / \mathrm{nl} 1037962$

Kwak, S.-Y., Kim, S. H., and Kim, S. S. (2001). Hybrid organic/inorganic reverse osmosis (RO) membrane for bactericidal anti-fouling. 1. Preparation and characterization of $\mathrm{TiO} 2$ nanoparticle self-assembled aromatic polyamide thinfilm-composite (TFC) membrane, 35, 2388-2394. doi: 10.1021/es0017099

Lee, K. P., Arnot, T. C., and Mattia, D. (2011). A review of reverse osmosis membrane materials for desalination-Development to date and future potential. J. Membr. Sci. 370, 1-22. doi: 10.1016/j.memsci.2010.12.036

Lee, S., Kim, S., Cho, J., and Hoek, E. M. V. (2007). Natural organic matter fouling due to foulant-membrane physicochemical interactions. Desalination 202, 377-384. doi: 10.1016/j.desal.2005.12.077

Leo, C. P. W.,Lee, P. C., Ahmad, A. L., and Mohammad, A. W. (2012). Polysulfone membranes blended with $\mathrm{ZnO}$ nanoparticles for reducing fouling by oleic acid. Sep. Purif. Technol. 89, 51-56. doi: 10.1016/j.seppur.2012.01.002

Leong, S., Razmjou, A., Wang, K., Hapgood, K., Zhang, X., and Wang, M. S. (2014). $\mathrm{TiO}_{2}$ based photocatalytic membranes: a review. J. Membr. Sci. 472, 167-184. doi: 10.1016/j.memsci.2014.08.016

Li, L. H., Deng, J. C., Deng, H. R., Liu, Z. L., and Xin, L. (2010). Synthesis and characterization of chitosan/ZnO nanoparticle composite membranes. Carbohydr. Res. 345:994. doi: 10.1016/j.carres.2010. 03.019

Li, N., Zhang, J., Tian, Y., Zhang, J., Zhan, W., Zhao, J. H., et al. (2016). Hydrophilic modification of polyvinylidene fluoride membranes by $\mathrm{ZnO}$ atomic layer deposition using nitrogen dioxide/diethylzinc functionalization. J. Membr. Sci. 514, 241-249. doi: 10.1016/j.memsci.2016.04.072

Li, R., Lou, Y., Xu, Y., Ma, G., Liao, B.-Q., Shen, L., et al. (2019). Effects of surface morphology on alginate adhesion: Molecular insights into membrane fouling based on XDLVO and DFT analysis. Chemosphere. 233, 373-380. doi: 10.1016/j.chemosphere.2019.05.262

Li, X., Li, J. S., Van der Bruggen, B., Sun, X. Y., Shen, J. Y., Hana, W. Q., et al. (2015). Fouling behavior of polyethersulfone ultrafiltration membranes functionalized with sol-gel formed $\mathrm{ZnO}$ nanoparticles. RSC $A d v$. 5, 50711-50719. doi: 10.1039/C5RA05783C

Li, Z., Wang, Y., Han, M., Wang, D., Han, S., Liu, Z., et al. (2020). Graphene oxide incorporated forward osmosis membranes with enhanced desalination performance and chlorine resistance. Front. Chem. 7:877. doi: $10.3389 /$ fchem.2019.00877

Liang, S., Xiao, K., Mo, Y., and Huang, X. (2012). A novel ZnO nanoparticle blended polyvinylidene fluoride membrane for anti-irreversible fouling. $J$. Membr. Sci. 394-395, 184-192. doi: 10.1016/j.memsci.2011.12.040 
Lin, D.-J., Chang, H.-H., Chen, T.-C., Lee, Y.-C., Cheng, L.-P. (2006). Formation of porous poly(vinylidene fluoride) membranes with symmetric or asymmetric morphology by immersion precipitation in the water/TEP/PVDF system. Euro. Polymer J. 42, 1581-1594. doi: 10.1016/j.eurpolymj.2006.01.027

Lin, H., Peng, W., Zhang, M., Chen, J., Hong, H., and Zhang, Y. J. D. (2013). A review on anaerobic membrane bioreactors: applications, membrane fouling and future perspectives. Desalination 314, 169-188. doi: 10.1016/j.desal.2013.01.019

Lin, H., Zhang, M., Wang, F., Meng, F., Liao, B.-Q., Hong, H., et al. (2014). A critical review of extracellular polymeric substances (EPSs) in membrane bioreactors: characteristics, roles in membrane fouling and control strategies. J.Membr. Sci. 460, 110-125. doi: 10.1016/j.memsci.2014.02.034

Lin, T., Lu, Z., and Chen, W. (2014). Interaction mechanisms and predictions on membrane fouling in an ultrafiltration system, using the XDLVO approach. J. Membr. Sci. 461, 49-58. doi: 10.1016/j.memsci.2014. 03.022

Liu, F., Hashim, N. A., Liu, Y., M., and Abed, R. M., Li, K. (2011). Progress in the production and modification of PVDF membranes. J. Membr. Sci. 375, 1-27. doi: $10.1016 /$ j.memsci.2011.03.014

Look, D. C. (2001). Recent advances in ZnO materials and devices. Mater. Sci. Eng. 80, 383-387. doi: 10.1016/S0921-5107(00)00604-8

Ma, H., Hakim, L. F., Bowman, C. N., and R.H.J.J.o.Davis, M. S. (2001). Factors affecting membrane fouling reduction by surface modification and backpulsing. J. Membr. Sci. 189, 255-270. doi: 10.1016/S0376-7388(01) 00422-7

Mahlangu, O. T., Nackaerts, R., Mamba, B. B., and Ard, V. (2017). Development of hydrophilic GO-ZnO/PES membranes for treatment of pharmaceutical wastewater. Water Sci. Technol. 76:501. doi: 10.2166/wst.2017.194

Mallada, R., and Menéndez, M. (2008). Inorganic Membranes: Synthesis, Characterization and Applications, Vol 13. Elsevier, 480.

Meng, F., Chae, S.-R., Drews, A., Kraume, M., Shin, H.-S., and Yang, F. (2009). Recent advances in membrane bioreactors (MBRs): Membrane fouling and membrane material. Water Res. 43, 1489-1512. doi: 10.1016/j.watres.2008.12.044

Ng, L. Y., Mohammad, A. W., Leo, C. P., and Hilal, N. (2013). Polymeric membranes incorporated with metal/metal oxide nanoparticles: a comprehensive review. Desalination 308, 15-33. doi: 10.1016/j.desal.2010.11.033

Padaki, M., Surya Murali, R., Abdullah, M. S., Misdan, N., Moslehyani, A., Kassim, M. A., et al. (2015). Membrane technology enhancement in oil-water separation. A review. Desalination 357, 197-207. doi: 10.1016/j.desal.2014.11.023

Pendergast, M. M., and Hoek, E. M. V. (2011). A review of water treatment membrane nanotechnologies. Energy Environ. Sci. 4, 1946-1971. doi: $10.1039 / \mathrm{c} 0 \mathrm{ee} 00541 \mathrm{j}$

Pintilie, S., Tiron, L. G., Lazăr, A. L., Vlad, M., Bîrsan, I. G., and Balta, S. (2018). The influence of $\mathrm{ZnO} / \mathrm{TiO} 2$ nanohybrid blending on the ultrafiltration polysulfone membranes. Mater. Plast. 55:4963. doi: 10.37358/MP.18.1.4963

Rabiee, H., Vatanpour, V., M. H., and Farahani, D. A., Zarrabi, H. (2015). Improvement in flux and antifouling properties of PVC ultrafiltration membranes by incorporation of zinc oxide ( $\mathrm{ZnO})$ nanoparticles. Sep. Purif. Technol. 156, 299-310. doi: 10.1016/j.seppur.2015.10.015

Schaep, J., and Vandecasteele, C. (2001). Evaluating the charge of nanofiltration membranes. J. Membr. Sci. 188, 129-136. doi: 10.1016/S0376-7388(01) 00368-4

Shao, P., and Huang, R. Y. M. (2007). Polymeric membrane pervaporation. J. Membr. Sci. 287, 162-179. doi: 10.1016/j.memsci.2006.10.043

She, Q., Wang, R., Fane, A. G., and Tang, C.Y. (2016). Membrane fouling in osmotically driven membrane processes: a review. J. Membr. Sci. 499, 201-233. doi: 10.1016/j.memsci.2015.10.040

Shen, L., Bian, X., Lu, X., Shi, L., Liu, Z., Chen, L., et al. (2012). Preparation and characterization of $\mathrm{ZnO} /$ polyethersulfone (PES) hybrid membranes. Desalination 293, 21-29. doi: 10.1016/j.desal.2012. 02.019

Shen, L., Cui, X., Yu, G., Li, F., Li, L., Feng, S., et al. (2017a). Thermodynamic assessment of adsorptive fouling with the membranes modified via layerby-layer self-assembly technique. J. Colloid Interface Sci. 494, 194-203. doi: 10.1016/j.jcis.2017.01.051
Shen, L., Wang, X., Li, R., Yu, H., Hong, H., Lin, H., et al. (2017b). Physicochemical correlations between membrane surface hydrophilicity and adhesive fouling in membrane bioreactors. J. Colloid Interface Sci. 505, 900-909. doi: $10.1016 /$ j.jcis.2017.06.090

Shen, L.-G., Lei, Q., Chen, J.-R., Hong, H.-C., He, Y.-M., and Lin, H.-J. (2015). Membrane fouling in a submerged membrane bioreactor: impacts of floc size. Chem. Eng. J. 269, 328-334. doi: 10.1016/j.cej.2015.02.002

Shirasaki, N., Matsushita, T., Matsui, Y., and Ohno, K. (2008). Effects of reversible and irreversible membrane fouling on virus removal by a coagulation-microfiltration system. J. Water Supply Res. T. 57, 501-506. doi: 10.2166/aqua.2008.048

Smith, P. J., Vigneswaran, S., Ngo, H. H., Ben-Aim, R., and Nguyen, H. (2006). A new approach to backwash initiation in membrane systems. J. Membr. Sci. 278, 381-389. doi: 10.1016/j.memsci.2005.11.024

Strathmann, H. (1981). Membrane separation processes. J. Membr. Sci. 9, 121-189. doi: 10.1016/S0376-7388(00)85121-2

Subramani, A., and Jacangelo, J. G. (2015). Emerging desalination technologies for water treatment: a critical review. Water Res. 75, 164-187. doi: 10.1016/j.watres.2015.02.032

Teng, J., Shen, L., He, Y., Liao, B.-Q., Wu, G., and Lin, H. (2018). Novel insights into membrane fouling in a membrane bioreactor: Elucidating interfacial interactions with real membrane surface. Chemosphere 210, 769-778. doi: 10.1016/j.chemosphere.2018.07.086

Teng, J., Shen, L., Xu, Y., Chen, Y., Wu, X.-L., He, Y., et al. (2020). Effects of molecular weight distribution of soluble microbial products (SMPs) on membrane fouling in a membrane bioreactor (MBR): novel mechanistic insights. Chemosphere 248:126013. doi: 10.1016/j.chemosphere.2020.126013

Tijing, L. D., Woo, Y. C., Choi, J. S., Lee, S., Kim, S. H., and Shon, H. K. (2015). Fouling and its control in membrane distillation-a review. J. Membr. Sci. 475, 215-244. doi: 10.1016/j.memsci.2014.09.042

Tran, N. H., Ngo, H. H., Urase, T., and Gind, K. Y.-H. (2015). A critical review on characterization strategies of organic matter for wastewater and water treatment processes. Biores. Technol. 193, 523-533. doi: 10.1016/j.biortech.2015.06.091

Van Der Bruggen, B., Vandecasteele, C., Van Gestel, T., Doyen, W., and Leysen, R. (2003). A review of pressure-driven membrane processes in wastewater treatment and drinking water production. Environ. Progr. 22, 46-56. doi: 10.1002/ep.670220116

Vörösmarty, C. J., Hoekstra, A. Y., Bunn, S. E., Conway, D., and Gupta, J. (2015). Fresh water goes global. Science 349, 478-479. doi: 10.1126/science.aac6009

Wang, C., de Bakker, J., Belt, C. K., Jha, A., Neelameggham, N. R., Pati, S., et al. (2013). Energy Technology 2014: Carbon Dioxide Management and Other Technologies. New Jersey, NJ: Wiley. doi: 10.1002/9781118888735

$\mathrm{Wu}, \mathrm{C} ., \mathrm{Xu}, \mathrm{T}$., and Yang, W. (2003). A new inorganic-organic negatively charged membrane: membrane preparation and characterizations. J. Membr. Sci. 224, 117-125. doi: 10.1016/j.memsci.2003.07.004

$\mathrm{Wu}$, J. S., and Xue, D. F. (2011). Progress of science and technology of $\mathrm{ZnO}$ as advanced material. Sci. Adv. Mater. 3, 127-149. doi: 10.1166/sam.2011.1144

Xu, Z., Wu, T., Shi, J., Wang, W., Teng, K., Qian, X., et al. (2016). Manipulating migration behavior of magnetic graphene oxide via magnetic field induced casting and phase separation toward high-performance hybrid ultrafiltration membranes. ACS Appl. Mater. Interfaces 8, 18418-18429. doi: 10.1021/acsami.6b04083

You, X., Teng, J., Chen, Y., Long, Y., Yu, G., Shen, L., et al. (2020). New insights into membrane fouling by alginate: Impacts of ionic strength in presence of calcium ions. Chemosphere 246:125801. doi: 10.1016/j.chemosphere.2019.125801

Yu, W., Liu, Y., Shen, L., Xu, Y., Li, R., Sun, T., and Lin, H. (2020). Magnetic field assisted preparation of PES-Ni@MWCNTs membrane with enhanced permeability and antifouling performance. Chemosphere 243, 125446. doi: 10.1016/j.chemosphere.2019.125446

Yu, W. M., Liu, Y., Xu, Y. C., Li, R. J., Chen, J. R., Liao, B. Q., et al. (2019). A conductive PVDF-Ni membrane with superior rejection, permeance and antifouling ability via electric assisted in-situ aeration for dye separation. J. Membrane Sci. 581, 401-412. doi: 10.1016/j.memsci.2019.03.083

Yuliwati, E., and Ismail, A. F. (2011). Effect of additives concentration on the surface properties and performance of PVDF ultrafiltration membranes for refinery produced wastewater treatment. Desalination 273, 226-234. doi: 10.1016/j.desal.2010.11.023 
Zhang, M., Hong, H., Lin, H., Shen, L., Yu, H., Ma, G., et al. (2018). Mechanistic insights into alginate fouling caused by calcium ions based on terahertz timedomain spectra analyses and DFT calculations. Water Res. 129, 337-346. doi: 10.1016/j.watres.2017.11.034

Zhang, M., Liao, B.-Q., Zhou, X., He, Y., Hong, H., Lin, H., et al. (2015). Effects of hydrophilicity/hydrophobicity of membrane on membrane fouling in a submerged membrane bioreactor. Biores. Technol. 175, 59-67. doi: 10.1016/j.biortech.2014.10.058

Zhang, X., Wang, Y., Liu, Y. F., Xu, J. L., Han, Y. D., and Xu, X. X. (2014). Preparation, performances of PVDF/ZnO hybrid membranes and their applications in the removal of copper ions. Appl. Surf. Sci. 316, 333-340. doi: 10.1016/j.apsusc.2014.08.004

Zhao, C., Xue, J., Ran, F., and Sun, S. (2013). Modification of polyethersulfone membranes-a review of methods. Progr. Mater. Sci. 58, 76-150. doi: 10.1016/j.pmatsci.2012.07.002

Zhao, L. H., Shen, L. G., He, Y. M., Hong, H. C., and Lin, H. J. (2015). Influence of membrane surface roughness on interfacial interactions with sludge flocs in a submerged membrane bioreactor. J. Colloid Interface Sci. 446, 84-90. doi: 10.1016/j.jcis.2015.01.009

Zhao, S., Yan, W. T., Shi, M. Q., Wang, Z., Wang, J. X., and Wang, S. C. (2015). Improving permeability and antifouling performance of polyethersulfone ultrafiltration membrane by incorporation of $\mathrm{ZnO}-\mathrm{DMF}$ dispersion containing nano- $\mathrm{ZnO}$ and polyvinylpyrrolidone. J. Membr. Sci. 478, 105-116. doi: 10.1016/j.memsci.2014. 12.050

Zhao, Y., Yu, W., Li, R., Xu, Y., Liu, Y., Sun, T., et al. (2019). Electric field endowing the conductive polyvinylidene fluoride (PVDF)-graphene oxide (GO)nickel (Ni) membrane with high-efficient performance for dye wastewater treatment. Appl. Surf. Sci. 483, 1006-1016. doi: 10.1016/j.apsusc.2019. 04.054

Conflict of Interest: The authors declare that the research was conducted in the absence of any commercial or financial relationships that could be construed as a potential conflict of interest.

Copyright (C) 2020 Shen, Huang, Liu, Li, Xu, Jakaj and Lin. This is an open-access article distributed under the terms of the Creative Commons Attribution License (CC $B Y)$. The use, distribution or reproduction in other forums is permitted, provided the original author(s) and the copyright owner(s) are credited and that the original publication in this journal is cited, in accordance with accepted academic practice. No use, distribution or reproduction is permitted which does not comply with these terms. 